\title{
THE EFFECT OF GIVING ASSIGNMENT METHODS ON STUDENTS' UNDERSTANDING OF THE SCIENCE CONCEPTS
}

\author{
Maimunah H Daud ${ }^{1}$, Maria Waldetrudis Lidi ${ }^{2}$ \\ 1,2 Universitas Flores, Ende, Indonesia \\ ${ }^{1}$ maimunahhdaud@gmail.com, ${ }^{2}$ waldetrudismaria1024@gmail.com
}

\begin{abstract}
The low score of students' science learning outcomes at SMPN 1 Ndona during the covid 19 pandemic were caused by the limited interactions between teachers and students. This was supported by limited resources in implementing online learning systems. Giving assignment method was one of methods that could be applied to overcome this problems. The purpose of this study was to determine the effect of giving assignment methods on students' understanding of science concepts during the Covid-19 pandemic. This study was a type of quantitative research using experimental methods and was carried out at SMPN 1 Ndona in October 2020. The design of this study was a pre-experimental design with one shot case study model. Data were collected through test techniques and the data were analyzed by the formula of test using SPSS 24. Based on the results of data analysis obtained from 30 students, the value of $t_{\text {count }}=31.44$ and $d f=29$ at the significant level $\alpha=0.05$; it was obtained sig.(2-tailed) $0.000<0.05$. Thus, $H_{0}$ was rejected and $H_{I}$ was accepted. This proved that giving assignment method influenced the students' understanding on the science concept at grade VII SMPN 1 Ndona.
\end{abstract}

Keywords: giving assignment method, understanding, science concept

\section{PENGARUH METODE PEMBERIAN TUGAS TERHADAP PEMAHAMAN KONSEP IPA SISWA}

\begin{abstract}
ABSTRAK
Rendahnya hasil belajar IPA kelas VII di SMPN 1 Ndona di masa pandemi covid 19 diakibatkan oleh keterbatasan interaksi antara guru dan siswa terlebih didukung oleh keterbatasan sumber daya dalam melaksanakan sistem pembelajaran dalam jaringan. Metode pemberian tugas menjadi salah satu metode yang dapat diterapkan untuk mengatasi permasalahan yang dihadapi. Tujuan dari penelitian ini adalah untuk mengetahui pengaruh metode pemberian tugas terhadap pemahaman konsep IPA siswa di masa pandemi covid 19. Penelitian ini merupakan jenis penelitian kuantitatif dengan menggunakan metode eksperimen dan dilaksanakan di SMPN 1 Ndona pada bulan Oktober tahun 2020. Rancangan penelitian menggunakan pre experimental design dengan model one shot case study. Teknik pengumpulan data menggunakan teknik tes sedangkan analisis data dengan uji t menggunakan SPSS 24. Berdasarkan hasil analisis data dengan jumlah sampel 30 orang diperoleh nilai $t_{\text {hitung }}=31.44$ dengan df $=29$ pada taraf signifikan $\alpha=0.05$ diperoleh sig.(2-tailed) $0.000<0.05$ maka $\mathrm{H}_{0}$ ditolak dan $\mathrm{H}_{1}$ diterima Hal ini membuktikan bahwa ada pengaruh metode pemberian tugas terhadap pemahaman konsep IPA siswa kelas VII SMPN 1 Ndona.
\end{abstract}

Kata Kunci: metode pemberian tugas, pemahaman, konsep IPA

\begin{tabular}{|c|c|c|}
\hline Submitted & Accepted & Published \\
\hline 26 Mei 2021 & 21 Juli 2021 & 29 Juli 2021 \\
\hline
\end{tabular}

\begin{tabular}{|l|l|l|l|l|}
\hline Citation & $:$ & $\begin{array}{l}\text { H Daud, M., \& Lidi, M.W. (2021). The Effect of Giving Assignment Methods on Students' Understanding of the Science } \\
\text { Concepts. Jurnal PAJAR (Pendidikan dan Pengajaran), 5(4), 1156-1162. DOI : } \\
\text { http://dx.doi.org/10.33578/pjr.v5i4.8424. }\end{array}$ \\
\hline
\end{tabular}

\section{PENDAHULUAN}

Pendidikan merupakan aspek yang sangat penting dalam membelajarkan manusia untuk mengembangkan potensi diri dan membentuk karakter agar menjadi manusia yang lebih baik. Dalam undang-undang No 20 tahun 2003 menyatakan bahwa pendidikan adalah usaha sadar dan terencana untuk mewujudkan suasana belajar dan proses pembelajaran agar siswa secara aktif mengembangkan potensi dirinya. Kualitas pendidikan tidak hanya ditentukan oleh sistem pendidikan akan tetapi juga ditentukan oleh tenaga pengajar. Tenaga pengajar yang dimaksudkan mampu memberikan pelajaran kepada siswa sehingga siswa mampu memahami pelajaran yang diberikan. Menurut Adiatman (2011), guru atau tenaga pengajar dalam menyajikan materi bukan hanya fokus pada teori saja, melainkan membantu siswa untuk berinteraksi dengan berbagai sumber 
belajar dalam mendapatkan pengetahuan, keahlian, dan keterampilan serta sikap yang menuju kepada perubahan tingkah laku baik secara kognitif, afektif, maupun secara psikomotorik melalui proses pembelajaran.

Pada masa covid-19 proses pembelajaran di Indonesia mengalami perubahan yakni beralih dari proses pembelajaran yang melibatkan tatap muka langsung ke pembelajaran menggunakan media internet yang lebih popular dengan istilah dalam jaringan (daring). Adaptasi akibat pandemi covid-19 ini pun terjadi di Sekolah Menengah Pertama Negeri 1 Ndona yakni pembelajaran melalui tatap muka hanya dilaksanakan di hari senin dengan mengikuti protokol kesehatan dan lima hari dilakukan melalui media internet. Namun, berdasarkan hasil wawancara dengan guru IPA di sekolah tersebut diketahui bahwa proses pembelajaran yang telah dilaksanakan belum memberikan hasil yang maksimal di mana sebesar $73 \%$ siswa belum mencapai kriteria ketuntasan minimal (KKM) yang telah ditetapkan. Rendahnya pemahaman konsep IPA siswa disebabkan oleh beberapa hal yakni keterbatasan akses internet, keterbatasan media belajar, minimnya interaksi antara guru dan siswa, perbedaan siswa dalam memahami materi, dan minimnya pengawasan dalam belajar. Hal serupa dikemukakan oleh Halawa dan Chrismastianto (2021), yaitu pembelajaran jarak jauh yang memanfaatkan teknologi memberikan kesulitan kepada beberapa siswa dalam mengakses dan memahami materi. Banyaknya tantangan yang dihadapi menuntut guru untuk menerapkan model atau metode pembelajaran yang tepat yang dapat menjangkau seluruh siswa dengan segala keterbatasan yang ada.

Salah satu metode pembelajaran yang dapat digunakan untuk mengatasi permasalahan tersebut adalah metode pemberian tugas. Adiatman (2011), mengungkapkan bahwa pemberian tugas yang dilakukan oleh guru bertujuan untuk melihat sejauh mana daya tangkap siswa setelah pembelajaran diberikan, sekaligus sebagai acuan untuk menilai kemampuan siswa terhadap materi yang telah diajarkan di kelas. Ditambahkan oleh Iqbal (2015), pemberian tugas adalah metode penyajian bahan dengan tujuan siswa melakukan kegiatan belajar dan dapat dilakukan dimana saja asal itu dapat dikerjakan. Perlu diketahui bahwa metode pemberian tugas tidak sama dengan pekerjaan rumah (PR). Pekerjaan rumah merupakan tugas terstruktur yang diberikan oleh guru kepada siswa untuk dikerjakan di rumah dengan waktu yang ditentukan, sedangkan dalam pemberian tugas tidak harus dikerjakan di rumah, melainkan dapat dikerjakan di laboratorium, perpustakaan, sekolah atau ditempat lainnya yang berhubungan dengan materi pelajaran yang diberikan (Rofiqah dkk., 2017). Sehingga dapat disimpulkan bahwa metode pemberian tugas adalah suatu cara interaksi belajar antara guru dan siswa berupa penyajian bahan pembelajaran dalam bentuk tugas tertentu agar diselesaikan siswa sebagai salah satu bentuk kegiatan belajarnya, dan kemudian dilaporkan sebagai hasil dari tugas tersebut tanpa terikat dengan tempat.

Metode pemberian tugas teruji dapat meningkatkan pemahaman siswa. Enanda dan Triyono (2016), berdasarkan temuannya mengemukakan bahwa penerapan metode pemberian tugas dapat meningkatkan motivasi belajar siswa sebesar $24.41 \%$ dan prestasi belajar sebesar $68.6 \%$ pada siswa SMK kelas X. Senada dengan temuan Damayanti (2016), yakni metode pemberian tugas terbukti dapat meningkatkan hasil belajar materi reaksi oksidasi reduksi pada siswa SMA kelas X. Purba (2019), penggunaan metode pemberian tugas pada siswa dapat meningkatkan hasil belajar sebesar $75 \%$ pada siswa SD kelas IV. Metode pemberian tugas memiliki beberapa kelebihan diantaranya adalah 1) siswa dilatih untuk belajar mandiri; 2) belajar lebih menarik karena tidak dibatasi oleh kelas; 3 ) siswa dapat menguji kemampuan diri sendiri dengan mengerjakan soal latihan dalam tugas; 4) dapat mengembangkan kemampuan siswa melalui interaksi langsung dengan lingkungan belajarnya (Ibrahim dkk., 2015).

Berdasarkan kajian hasil penelitian yang relevan di atas, maka penulis tertarik untuk menerapkan metode pemberian tugas pada pembelajaran IPA di kelas VII SMPN 1 Ndona melalui penelitian dengan judul pengaruh metode pemberian tugas terhadap pemahaman konsep IPA 
siswa. Penerapan metode pemberian tugas bertujuan meningkatkan interaksi antara guru dan siswa melalui kegiatan belajar yang berdampak pada peningkatan pemahaman pada konsep IPA. Selain itu, penerapan metode ini merupakan salah satu cara yang tepat untuk dilakukan di masa pandemi yang membatasi kegiatan tatap muka antara guru dan siswa sehingga guru tetap dapat memantau kegiatan belajar siswa melalui tugas yang diberikan.

\section{METODE PENELITIAN}

\section{Jenis Penelitian}

Jenis penelitian yang digunakan adalah penelitian kuantitatif dengan menggunakan metode eksperimen. Rancangan eksperimen dalam penelitian ini adalah one shot-case study yakni satu kelompok diberi perlakuan berupa metode pemberian tugas dan selanjutnya diobservasi hasilnya. Desain penelitian disajikan pada Gambar 1.

\section{X $\mathbf{0}$}

\section{Gambar 1. Desain one shot-case}

$\mathrm{X}$ adalah: perlakuan yang diberikan

0 adalah observasi (hasil dari perlakuan) (Sugiyono, 2017)

\section{Waktu dan Tempat Penelitian}

Penelitian dilaksanakan pada tanggal 1 Oktober sampai 31 Oktober tahun 2020 di Sekolah Menengah Pertama Negeri 1 Ndona.

\section{Subyek Penelitian}

Populasi dalam penelitian ini adalah seluruh siswa kelas VII SMPN 1 Ndona yang berjumlah 180 orang sedangkan sampel yang diambil sebanyak 30 orang dengan teknik pengambilan sampel menggunakan teknik purposive sampling yakni berdasarkan pertimbangan-pertimbangan tertentu.

\section{Teknik Pengumpulan Data}

Data yang dikumpulkan dalam penelitian ini menggunakan teknik tes untuk mengukur besarnya pengaruh perlakuan pada sampel berupa hasil belajar siswa dan teknik wawancara sebagai studi pendahuluan.

\section{Teknik Analisis data}

Data yang dikumpulkan dalam penelitian ini adalah hasil belajar menggunakan instrumen lembar soal tes pemahaman siswa. Setelah diberi perlakuan dilakukan tes untuk mengetahui hasil belajar siswa. Selanjutnya data dianalisis menggunakan SPSS 24. Analisis data dalam penelitian ini adalah uji t. Sebelum uji t dilakukan terlebih dahulu adalah uji prasyarat analisis yaitu menggunakan uji normalitas dan uji hipotesis. Uji normalitas dilakukan dengan bantuan software version 24 menggunakan uji Kolmogorov Smirnov. Untuk mentukan data berdistribusi normal atau tidak, dengan cara melihat nilai Asymp. Sig (probabilitas). Dimana jika nilai Asympsig. (2tailed) lebih dari 0.05 (sig $>(0.05)$ maka data berdistribusi normal sebaliknya, jika nilaiAsympsig. (2-tailed) kurang dari 0.05 (sig) < 0.05 maka data tidak berdistribusi normal.

\section{Prosedur Penelitian}

Penelitian ini dilaksanakan mengikuti tahaptahap berikut:

1. Membuat dan menyusun instrumen penelitian

2. Melaksanakan validasi instrumen penelitian

3. Memberikan perlakuan kepada siswa berupa pembelajaran IPA dengan metode pemberian tugas

4. Memberikan tes

5. Pengolahan dan analisis data

6. Membahas hasil penelitian sesuai dengan teori yang dirujuk

7. Membuat kesimpulan dari hasil penelitian.

8. Membuat kesimpulan dan rekomendasi. 


\section{HASIL DAN PEMBAHASAN}

Hasil Penelitian

Data yang dikumpulkan adalah hasil tes pemahaman konsep IPA menggunakan instrumen lembar soal. Data ini dianalisis menggunakan
SPSS 24 dengan tujuan untuk mengukur ada tidaknya pengaruh metode pemberian tugas terhadap pemahaman konsep IPA. Rangkuman hasil analisis data disajikan pada Tabel 1.

Tabel 1. Hasil Uji Tes Pemahaman Konsep IPA Siswa

\begin{tabular}{cc}
\hline \multicolumn{2}{c}{ Descriptive Statistics } \\
Hasil Uji Tes Pemahaman Konsep IPA Siswa \\
\hline $\mathrm{N}$ & 30 \\
& 0 \\
Mean & 85.00 \\
Std. Deviation & 2.613 \\
Minimum & 80 \\
Maximum & 90 \\
\hline
\end{tabular}

Tabel 1 menunjukkan bahwa nilai minimum yang diperoleh siswa adalah 80 dan nilai maksimumnya adalah 90 . Nilai rata-rata atau mean merupakan jumlah semua nilai dalam suatu sebaran dibagi dengan jumlah kasus adalah 85.00 selain itu terlihat juga nilai standar deviasi yaitu suatu ukuran yang menggambarkan tingkat penyebaran data dari rata-rata $=2.613$. Hasil uji tes pemahaman konsep siswa termasuk dalam kategori baik karena melebihi standar KKM yaitu 70. Hasil tes pemahaman siswa pada Tabel 1 selanjutnya dapat digambarkan dalam bentuk diagram batang pada Gambar 2.

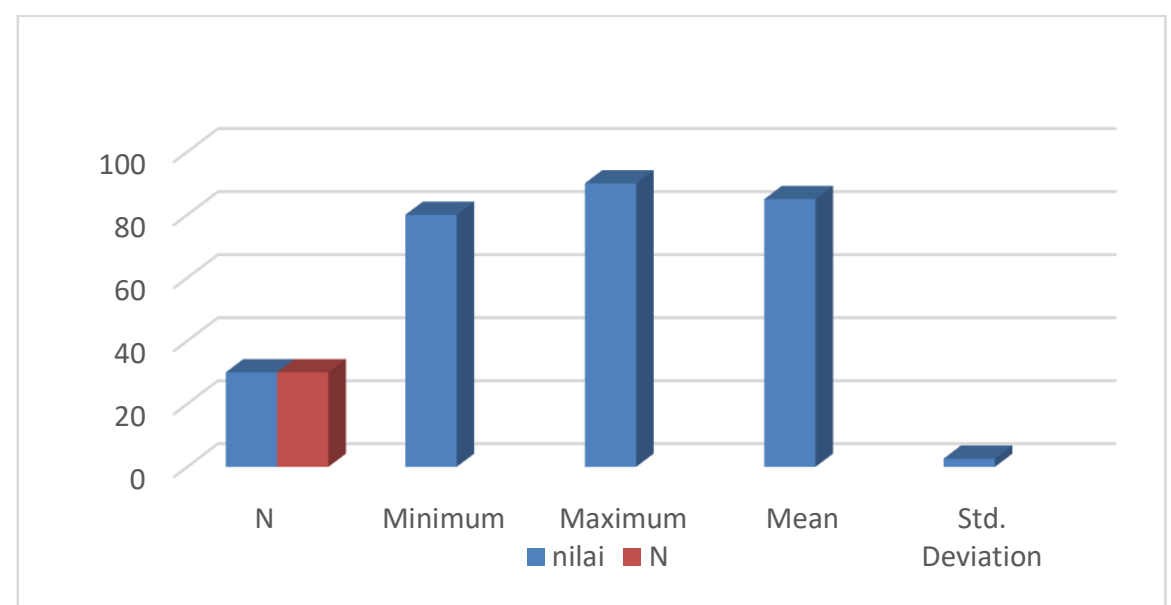

Gambar 2. Diagram Hasil Uji Tes Pemahaman Konsep IPA Siswa

Rentangan nilai tes siswa disajikan dalam

Tabel 2 dan dideskripsikan secara ringkas melalui diagram batang pada Gambar 3 
Jurnal PAJAR (Pendidikan dan Pengajaran)

Volume 5 Nomor 3 April 2021 | ISSN Cetak : 2580 - 8435 | ISSN Online : 2614 - 1337

DOI : http://dx.doi.org/10.33578/pjr.v5i4.8424

Tabel 2. Rentangan Nilai Uji Tes Pemahaman Konsep IPA Siswa

\begin{tabular}{cccc}
\hline $\begin{array}{c}\text { Rentangan } \\
\text { Nilai }\end{array}$ & Kriteria & Jumlah Siswa & \% Jumlah Siswa \\
\hline $90-100$ & Sangat Baik & 1 & $3 \%$ \\
$81-89$ & Baik & 28 & $94 \%$ \\
$70-80$ & Cukup Baik & 1 & $3 \%$ \\
$<70$ & Kurang Baik & 0 & $0 \%$ \\
\multicolumn{2}{c}{ Jumlah Sampel } & 30 & $100 \%$ \\
\hline
\end{tabular}



Gambar 3. Diagram Rentangan Nilai Uji Tes Pemahaman Konsep IPA Siswa

Berdasarkan data hasil penelitian maka dilakukan uji normalitas data untuk mengetahui apakah data berdistribusi normal atau tidak sebelum dilanjutkan dengan uji hipotesis. Hasil uji normalitas dan uji hipotesis dijelaskan sebagai berikut.

\section{Uji Normalitas}

Hasil uji normalitas data disajikan pada Tabel 3.

Tabel 3. Uji Normalitas

\begin{tabular}{|c|c|c|c|c|c|c|}
\hline \multicolumn{7}{|c|}{ Tests of Normality } \\
\hline \multirow{5}{*}{$\begin{array}{l}\text { Hasil Uji } \\
\text { Tes } \\
\text { Pemahaman } \\
\text { Konsep IPA } \\
\text { Siswa }\end{array}$} & \multicolumn{3}{|c|}{ Kolmogorov-Smirnov ${ }^{\mathrm{a}}$} & \multicolumn{3}{|c|}{ Shapiro-Wilk } \\
\hline & Statistic & $\mathrm{Df}$ & Sig. & Statistic & $\mathrm{df}$ & Sig. \\
\hline & .100 & 30 & $.200^{*}$ & .975 & 30 & .685 \\
\hline & & & & & & \\
\hline & & & & & & \\
\hline
\end{tabular}

Berdasarkan hasil perhitungan diperoleh nilai signifikan hasil belajar $0.200>0.05$, maka dapat disimpulkan bahwa data hasil uji tes pemahaman konsep IPA siswa berasal dari populasi berdistribusi normal sehingga dapat dilanjutkan dengan uji hipotesis. 


\section{Uji Hipotesis}

Dalam penelitian ini menggunakan one sample test, pengujiannya dilakukan dengan bantuan SPSS 24. Dasar pengambilan keputusan adalah jika signifikan (sig 2- tailed) $<0.05$ maka $\mathrm{H}_{0}$ ditolak dan $\mathrm{H}_{1}$ diterima. Berikut ini disajikan Tabel 4 hasil uji hipotesis.

Tabel 4. Uji Hipotesis Hasil Tes Pemahaman Konsep IPA Siswa

\begin{tabular}{|c|c|c|c|c|c|c|}
\hline \multirow{4}{*}{ Hasil Uji } & \multicolumn{6}{|c|}{$\begin{array}{c}\text { One-Sample Test } \\
\text { Test Value }=70\end{array}$} \\
\hline & & & Sig. (2- & Mean & $95 \%$ Confi & $\begin{array}{l}\text { nterval of the } \\
\text { ice }\end{array}$ \\
\hline & $\mathrm{t}$ & df & tailed) & Difference & Lower & Upper \\
\hline & 31.44 & 29 & .000 & 15.000 & 14.02 & 15.98 \\
\hline
\end{tabular}

Berdasarkan perhitungan SPSS, dengan jumlah siswa 30 orang pada taraf signifikan 0.000 dan diperoleh nilai $t_{\text {hitung }}=31.44$ dengan $\mathrm{df}=29$ pada taraf signifikan $\alpha=0.05$ dari tabel diperoleh sig.(2-tailed) $0.000<0.05$ maka $\mathrm{H}_{0}$ ditolak dan $\mathrm{H}_{1}$ diterima, maka data hasil uji $\mathrm{t}$ dapat diambil kesimpulan bahwa ada pengaruh metode pemberian tugas terhadap pemahaman konsep IPA siswa kelas VIII SMPN 1 Ndona.

Berdasarkan uraian diatas, hasil analisis data secara deskriptif statistik menunjukan bahwa terdapat pengaruh yang signifikan metode pemberian tugas terhadap pemahaman konsep IPA siswa kelas VII SMPN 1 Ndona. Tabel 1 menunjukkan bahwa rata-rata hasil tes pemahaman konsep siswa adalah 85.00 dan melebihi standar KKM yaitu 70. Nilai yang diperoleh siswa berada pada kategori baik yang tercantum pada tabel 2 dan dirangkum pada gambar 3. Hal ini diperkuat dengan uji hipotesis yaitu nilai sig. $(2$-tailed $)<0.05$ dan diperoleh nilai sig. $(2$-tailed $)<0.05$ maka dapat dikatakan $\mathrm{H}_{0}$ ditolak dan $\mathrm{H}_{1}$ diterima jadi ada pengaruh metode pemberian tugas terhadap pemahaman konsep IPA siswa kelas VIII SMPN 1 Ndona.

Temuan penelitian ini secara jelas membuktikan bahwa penerapan metode pemberian tugas berpengaruh dalam meningkatkan pemahaman siswa di masa pandemi Covid 19. Hal tersebut sesuai dengan temuannya Halawa dan Chrismastianto (2021), penerapan metode pemberian tugas di masa Covid 19 dapat merangsang keterlibatan siswa dalam mencapai tujuan pembelajaran walaupun materi dikirimkan melalui google classroom. Metode pemberian tugas dapat membantu guru memantau aktivitas belajar siswa melalui tugas yang diberikan walaupun dibatasi oleh berbagai hambatan yang dihadapi siswa. Bhakti (2017), mengemukakan bahwa metode pemberian tugas dapat meningkatkan pemahaman siswa terhadap konsep yang dipelajari karena menuntut siswa untuk menyelesaikan tugas yang diberikan. Tidak hanya itu, pemberian tugas dapat merangsang siswa untuk melakukan latihan ataupun mengulangi materi yang telah dipelajari sehingga dapat memperdalam pemahamannya (Iryani, 2017). Tujuan dari metode pemberian tugas adalah untuk memelihara dan memantapkan tingkah laku atau ingatan dari pelajaran yang telah dipelajari, juga melatih keterampilan, konsep, dan prinsip yang baru saja dikembangkan, dan dapat juga bermanfaat dalam menerapkan pelajaran tertentu di kehidupan sehari-hari (Iqbal, 2015). Selain itu, Sehingga dapat disimpulkan penggunaan metode pemberian tugas di masa pandemi yang membatasi interaksi langsung antara guru dan siswa dapat menjadi salah satu alternatif metode pembelajaran yang dapat digunakan. Hal ini disebabkan karena metode ini membantu guru untuk membimbing dan memantau kegiatan belajar siswa melalui tugas yang diberikan meskipun intensitas tatap muka langsung antara guru dan siswa berkurang.

\section{SIMPULAN DAN REKOMENDASI}

Berdasarkan hasil pembahasan di atas dapat disimpulkan bahwa metode pemberian tugas berpengaruh secara signifikan terhadap pemahaman konsep IPA di SMPN 1 Ndona yang mana hasil belajar siswa sudah mencapai bahkan melebihi nilai kriteria ketuntasan minimal yang telah ditetapkan yaitu 70. Diharapkan kepada para 
guru untuk dapat menggunakan variasi metode dan model pembelajaran yang mengacu pada kebutuhan siswa khususnya di masa pandemi yang membutuhkan banyak dukungan dari berbagai pihak bagi peningkatan kualitas pendidikan. Perlu dilakukan penelitian lanjutan tentang pengaruh metode pemberian tugas terhadap minat dan motivasi siswa dalam belajar terutama di masa pandemi covid 19 ini.

\section{DAFTAR PUSTAKA}

Adiatman. (2011). Efektifitas Penerapan Metode Pemberian Tugas (Resitasi) Terhadap Hasil Belajar Siswa Dalam Mata Pelajaran Biologi Kelas XI IPA SMA Negeri I Sungguminasa Kabupaten Gowa. Jurusan Pendidikan Biologi Universitas Islam Negeri Alaudin Makassar.

Bhakti, Y. B. (2017). Meningkatkan Hasil Belajar Fisika Menggunakan Metode Pemberian Tugas Terstruktur. Jurnal Pendidikan Fisika, $V$ (2), 138-147. DOI: 10.24127/jpf.v5i2.922

Damayanti, M. (2016). Pengaruh Pemberian Tugas Terstruktur Dengan Umpan Balik Individual Terhadap Hasil Belajar Siswa. Jurnal saintifik, 2 (1), 46-53. DOI: 10.31605/saintifik.v2i1.95

Enanda, A dan Triyono, M.B. (2016). Penerapan Metode Pemberian Tugas Pembuatan MIND MAPPING Untuk Meningkatkan Motivasi dan Prestasi Belajar Siswa. Jurnal Dinamika, 1 (1), 32-36. DOI: 10.21831/dinamika.v1i1.11454

Halawa, E dan Chrismastianto, I. A. W. (2021). Penerapan Metode Resitasi Untuk Meningkatkan Keterlibatan Aktif Siswa Dalam Pencapaian Tujuan Pembelajaran Sejarah Kelas X-IPS. Jurnal Kairos, 1 (1), E-ISSN 27752534.

Ibrahim, A. A., Yani, A., dan Haris, A. (2015). Pengaruh Penggunaan Metode Pemberian Tugas Terstruktur Terhadap Hasil Belajar Fisika Kelas XI SMA Negeri 22 Makassar. Jurnal Pendidikan
Fisika, 3 (2), 150-157. DOI: 10.26618/jpf.v3i2.262

Iryani, J. (2017). Peranan Metode Pemberian Tugas Terstruktur Terhadap Hasil Belajar Fisika Peserta Didik kelas X SMA Negeri 10 Makassar. Jurnal Pendidikan Fisika, 5 (2), 175-185. DOI: $10.26618 /$ jpf.v5i2.681

Iqbal, M. M. (2015). Penggunaan Metode Pemberian Tugas dalam Meningkatkan Hasil Belajar Bahasa dan Sastra Indonesia Siswa Kelas VIII SMP Muhammadiyah Parakan Tangsel Tahun Pelajaran 2014/2015. Jurusan Pendidikan Bahasa dan Sastra Universitas Islam Negeri Syarif Hidayatullah.

Purba, F. J. (2019). Pengaruh Metode Pemberian Tugas Terhadap Hasil Belajar Siswa. Jurnal Inovasi Pembelajaran Fisika, 7 (1), 15-18. DOI: 10.24114/inpafi.v7i1.13504

Rofiqah, S. A., Erwin, Gunarto, W. (2017). Pengaruh Pemberian Tugas Mandiri Terstruktur Terhadap Hasil Belajar Fisika Madrasah Tsanawiyah Nurul Huda. Jurnal Inovasi Pendidikan Fisika dan Riset Ilmiah, 1 (1), 37-40. DOI: $10.30599 /$ jipfri.v1i1.43

Sugiyono. (2017). Metode Penelitian Pendidikan: Pendekatan Kuantitatif, Kualitatif, dan $R \& D$. Bandung: Alfabeta. 